\title{
Erratum to: Comparison of PI-RADS 2, ADC histogram-derived parameters, and their combination for the diagnosis of peripheral zone prostate cancer
}

\author{
W. C. Lin, ${ }^{1,2}$ A. C. Westphalen, ${ }^{1,3}$ G. E. Silva, ${ }^{4}$ S. Chodraui Filho, ${ }^{5}$ R. B. Reis, ${ }^{6}$ \\ V. F. Muglia ${ }^{5}$ \\ ${ }^{1}$ Department of Radiology and Biomedical Imaging, University of California, San Francisco, 505, Parnassus Av., San Francisco, \\ CA 94143, USA \\ ${ }^{2}$ School of Medicine, Department of Radiology, China Medical University and Hospital, Taichung, Taiwan \\ ${ }^{3}$ Departments of Radiology and Biomedical Imaging, and Urology, University of California, San Francisco, San Francisco, USA \\ ${ }^{4}$ Department of Pathology, Ribeirão Preto School of Medicine, University of São Paulo, São Paulo, Brazil \\ ${ }^{5}$ Division of Radiology, Department of Internal Medicine, Ribeirão Preto School of Medicine, University of São Paulo, São Paulo, \\ Brazil \\ ${ }^{6}$ Division of Urology, Department of Surgery, Ribeirão Preto School of Medicine, University of São Paulo, São Paulo, Brazil
}

\section{Erratum to: Abdom Radiol (2016) 41(11):2209-2217 DOI: $10.1007 / \mathrm{s} 00261-016-0826-4$}

Unfortunately, the original version of this article contained a mistake. The affiliation for the first author, W. C. Lin, should read as follows: School of Medicine, Department of Radiology, China Medical University and Hospital, Taichung, Taiwan. It is now corrected.

The online version of the original article can be found under doi: 10.1007/s00261-016-0826-4.

Correspondence to: A. C. Westphalen; email: AntonioCarlos.West phalen@ucsf.edu 